\title{
Alunos com deficiência: investigação e análise das condições de atendimento de um Instituto Federal de Educação, Ciência e Tecnologia no Brasil
}

\author{
Cesar Gomes de Freitas* \\ Cristina Maria Delou** \\ Helena Carla Castro***
}

\section{Resumo}

Instituiçóes de ensino buscam oferecer educação de forma inclusiva a todos os estudantes. Contudo, a acessibilidade ainda não é garantida de forma plena para todos os indivíduos com necessidades especiais. Este público tem o direito à educação, mas ainda tem que ser lembrado, considerando os diferentes ambientes que permeiam suas vidas, incluindo os ambientes educacionais de nível superior. Neste trabalho, investigamos as condiçôes institucionais oferecidas por um dos 38 Institutos Federais que compóem a Rede Federal de Educação Profissional, Científica e Tecnológica. Foram comparados um Instituto Federal com a Universidade Federal Fluminense que já trabalha com a questão de acessibilidade em seus campi. Os resultados mostram que existe a meta de adequaçáo nos quatro campi do referido Instituto Federal. Contudo, a completude do atendimento ainda se distancia da prestação de uma educação verdadeiramente inclusiva. Os dados deste trabalho indicam uma necessidade de que esta Instituição promova a adequaçáo de forma contínua para atender ao público em foco, podendo inferir que este quadro de inadequaçáo possa estar sendo compartilhado por outros Institutos Federais.

Palavras-chave: Acessibilidade; Educação especial; Institutos Federais.

* Doutorando em Ensino em Biociências e Saúde pelo Instituto Oswaldo Cruz/Fiocriz e docente do Instituto Federal do Acre, Rio Branco, Acre, Brasil.

** Professora doutora da Universidade Federal Fluminense, Niterói, Rio de Janeiro, Brasil.

*** Professora doutora da Universidade Federal Fluminense, Niterói, Rio de Janeiro, Brasil. 


\title{
Students with disabilities: investigation and analysis of conditions of service a Federal Institute of Education, Science and Technology in Brazil
}

\begin{abstract}
Educational institutions seek to offer inclusive education to all students. However, accessibility is still not fully guaranteed to all individuals with special needs. The public has the right of proper education, but it still has to be remembered, considering the different environments that permeate their lives, including the top-level educational environments. In this paper, we investigate the institutional conditions offered by one of the 38 Federal Institutions that compose the Federal Network of Professional Education, science and technology. A Federal Institute was compared with the Universidade Federal Fluminense which already works with the issue of accessibility in their campuses. The results show that there is the goal of fitness on the four campuses of the Federal Institute. However, the completeness of care still distances itself from the provision of a truly inclusive education. The data from this work indicates a need for this institution to promote continuous adequacy in order to attend its public and it also infers that, possibly, this framework of inadequacy can be shared by other Federal Institutions.
\end{abstract}

Keywords: Accessibility; Special education; Federal Institutes.

\section{Introdução}

$\mathrm{Na}$ educação formal ou não formal, dotar os espaços de aprendizagem de condições efetivas para a inclusão de alunos com deficiência é uma missão não apenas das instituiçôes de ensino, mas também de toda a sociedade. De acordo com Mazzotta (2011), a defesa da cidadania e do direito à educaçáo das pessoas com deficiência é algo recente em nossa sociedade.

A adequação dos espaços físicos, dos recursos pedagógicos e, também da formação e capacitação de professores e gestores tem sido continuamente requisitados pela sociedade brasileira. Contudo, considerando-se que acessibilidade é mais do que a questão dos espaços físicos, outros parâmetros ainda têm que ser trabalhados como a comunicação e capacitação profissional, os recursos didáticos e tecnológicos, dentre outros, principalmente no que tange ao atendimento das pessoas com deficiência (GUERREIRO, 2012).

A sociedade evoluiu significativamente quando se avalia o tratamento dispensado às pessoas com necessidades especias, considerando-se principalmente épocas remotas na qual era comum abandonar crianças com deficiência nas florestas ou jogá-las nos rios, sendo que, para aqueles que chegavam à vida adulta, o tratamento era também cruel (SMITH, 2008). Nesta lenta, mas gradual evoluçăo, o atendimento, a prestação de serviços e a inclusão efetiva das pessoas com deficiência na da sociedade ganhou qualidade e importância, geralmente com o auxílio de legislação específica. 
Nas últimas décadas, o número de alunos com deficiência nas redes de ensino cresceu. Foi registrado um acréscimo de 102,78\% entre os anos de 2007 e 2012, quando a escola pública registrava em torno de 306 mil alunos com deficiência, passando a registrar 620 mil (CHAVES, 2014). Contudo, os problemas ainda existem e a exclusão pode ser observada nos resultados da aprendizagem desse alunado. Segundo Caiado, Jesus e Baptista:

"Os atendimentos educacionais especializados aos alunos com deficiência, transtornos globais do desenvolvimento e altas habilidades/superdotação têm sido um dos grandes desafios para os profissionais da Educaçáo, principalmente no que se refere à sua articulação com o ensino comum”. (CAIADO; JESUS; BAPTISTA, 2001, p. 17).

A Universidade Federal Fluminese (UFF) é uma das universidades que possui trabalhos publicados apontando as experiências e avanços em relação ao atendimento ofertado a este público específico (DELOU et al., 2011-2013; MERÇON, et al., 2013; LYRIO, et al., 2014; SOUZA, et al., 2012; CARDOSO et al., 2014). A busca dessa Universidade Federal em melhorar o atendimento aos alunos com deficiência (DELOU et al., 2012c) resultou, entre outras conquistas, como a oferta do programa de extensão Escola de Inclusão (DELOU et al., 2012a; 2012b), além da criação do Curso de Mestrado Profissional em Diversidade e Inclusão,no Instituto de Biologia, envolvendo docentes no atendimento acadêmicoa discentes com deficiêncianesse espaço acadêmico (DELOU et al., 2013).

Atualmente, o desafio da inclusão está presente na Rede Federal de Educação Profissional, Científica e Tecnológica do Brasil. A Rede é constituída por 38 institutos, mais de 400 unidades que oferecem cursos gratuitos do nível médio até o pós-doutoramento (REDE, 2013). A grande abrangência e importância devido a sua capacidade de formar cidadáos habilitados e preparados para a vida profissional, faz com que um perfil inclusivo na forma de divulgação seja determinante para contribuir com os índices de formação de pessoas com deficiência.

No intuito de manter a sua missão, o Instituto Federal de Educação, Ciência e Tecnologia em análise, denominado neste trabalho pelas iniciais IFECT, começou as suas atividades acadêmicas a partir de 2010, para aproximadamente 350 discentes matriculados em nove cursos dos eixos de Recursos Naturais, Ambiente, Saúde e Segurança e Gestão e Negócios, distribuídos em quatro campi.

Atualmente, o IFECT oferece cursos de Formação Inicial e Continuada de Trabalhadores, cursos técnicos de Nível Médio nas formas integrada ao ensino médio e subsequente, cursos técnicos de nível médio modalidade EJA com o programa PROEJA, cursos superiores de Tecnologia, além de Programas, como Mulheres Mil, CERTIFIC e PRONATEC.

Baseado na perspectiva do ensino para todos, o objetivo deste trabalho foi realizar um estudo de caso, investigando e analisando as condiçôes de atendimento aos estudantes com deficiência oferecidas institucionalmente pelo Instituto Federal em análise (IFECT), um dos Institutos da Rede Federal. Nosso trabalho ainda compara 
as condiçôes deste Instituto com as ofertadas pela Universidade Federal Fluminense (UFF), pontuando as principais diferenças existentes entre as duas instituiçóes, no sentido de identificar pontos a serem melhorados na perspectiva no ensino técnico -profissional para o público com deficiência do IFECT e de servir de orientaçáo para outros Institutos Federais brasileiros.

\section{Materiais e métodos}

Este trabalho utilizou a abordagem quali-quantitativa que empregou questionários (com questôes fechadas, abertas e semiabertas) e entrevista com roteiro semi -estruturado como formas de avaliação (CAREGNATO; MUTTI, 2006).

A escolha das instituiçóes envolvidas resultou do objetivo de comparar o atendimento aos alunos com deficiência, oferecido em uma instituiçáo com implantação recente, e consequentemente com poucos anos de existência, com o atendimento oferecido em uma instituição com vários anos de existência e com trabalho de destaque na Educação Especial e Inclusiva. O Instituto Federal escolhido localiza-se em um Estado da Regiáo Norte do país, enquanto a Universidade Federal Fluminense localiza-se na Regiáo Sudeste, no Estado do Rio de Janeiro.

Após a aprovação do Comitê de Ética e Pesquisa do Instituto Oswaldo Cruz da Fiocruz, parecer número 644.846. A pesquisa foi realizada entre Outubro de 2013 e Fevereiro de 2014 no sentido de verificar as condiçóes oferecidas institucionalmente aos alunos com deficiência por um Instituto Federal e por uma Universidade Federal. Para isso, foram aplicados juntamente com o termo de livre consentimento esclarecido, questionários contendo 12 (doze) questóes, aos quatro coordenadores dos Núcleos de Atendimento às Pessoas com Necessidades Específicas (NAPNE) de cada um dos quatro campi do IFECT em quatro cidades, como também à coordenadora do núcleo de acessibilidade e inclusão da UFF.

Além dos questionários quantitativos, foram realizadas entrevistas que possibilitaram novas informaçóes e esclarecimentos, por meio de questóes que emergiram no contexto das entrevistas (PATTON, 1980 apud COHEN et al., 2001).

Após a aplicação dos questionários e realização de entrevistas, o material organizado foi interpretado com o suporte do referencial teórico-conceitual pesquisado. As respostas para as perguntas dos questionários foram categorizadas na proposta de análise de conteúdo de Bardin (2002), considerando as principais ideias e concepçôes apresentadas. Por se tratar de um estudo qualitativo, alguns dados tiveram tratamento quantitativo e foram apresentados por meio de gráficos em frequência simples, de acordo com a proposta de Trivińos (2008). Foi feita a análise de discurso (Bardin, 2002) dos entrevistados com vistas a identificar categorias, reflexo a construçáo social do participante (CAREGNATO; MUTTI, 2006).

\section{Resultados e discussão}

Conforme relatado na literatura, os desafios na área de atendimento educacional dos alunos com deficiência são enormes, sendo uma luta necessária para garan- 
tir a cidadania plena dos alunos com deficiencia. A Política Nacional da Educação Especial na Perspectiva da Educação Inclusiva (Brasil, 2008) relata que as açôes e movimentos pela inclusão, além de um fenômeno mundial que envolve açôes políticas, culturais, sociais e pedagógicas, são desencadeadas em defesa do direito de todos os alunos compartilharem os mesmos espaços, aprendendo e participando, sem nenhum tipo de discriminação.

Os dados encontrados na nossa pesquisa demonstraram que o IFECT aderiu à perspectiva da educaçáo inclusiva no ensino superior a partir da criação dos Núcleos de Atendimento as Pessoas com Necessidades Específicas (NAPNES) em todos os seus campis. Trata-se de uma decisão política instituída pela SETEC (Secretaria de Educação Profissional e Tecnológica) em parceria com a Secretaria de Educação Continuada, Alfabetização, Diversidade e Inclusão (Secadi), ambas vinculadas ao MEC (Ministério da Educação).

\begin{abstract}
A Política Nacional de Educação Especial na Perspectiva da Educação Inclusiva tem como objetivo assegurar a inclusão escolar de alunos com deficiência, transtornos globais do desenvolvimento e altas habilidades/superdotação, orientando os sistemas de ensino para garantir: acesso ao ensino regular, com participação, aprendizagem e continuidade nos níveis mais elevados do ensino; transversalidade da modalidade de educaçáo especial desde a educação infantil até a educaçáo superior; oferta do atendimento educacional especializado; formação de professores para o atendimento educacional especializado e demais profissionais da educaçáo para a inclusão; participação da família e da comunidade; acessibilidade arquitetônica, nos transportes, nos mobiliários, nas comunicaçóes e informação; e articulação intersetorial na implementação das políticas públicas. (BRASIL, 2008, p. 14).
\end{abstract}

No período em que a pesquisa foi realizada as coordenaçóes dos NAPNEs nos campi do IFECT eram ocupadas por uma professora (Campus 2) e por três Assistentes Sociais (Campus 1, Campus 3 e Campus 4), enquanto na UFF a funçáo era ocupada por uma jornalista cadeirante, aposentada. Todos os participantes da presente pesquisa têm pós-graduação/especializaçáo como último nível de escolaridade, sendo três do sexo feminino e um do sexo masculino, no IFECT, e uma do sexo feminino na UFF.

No final de 2013, o IFECT atendia ao total de 30 (trinta) estudantes com vários tipos de deficiências, dos quais 18 (dezoito), eram oriundos do campus 1, 08 (oito) do campus 2 e 04 (quatro) do campus 3. O campus 4 não possuía nenhum estudante com deficiência. O IFECT possuía $23,07 \%$ dos alunos da UFF, que registrava, na época da pesquisa, 130 alunos com algum tipo de deficiência, identificadas por meio de censo institucional. 

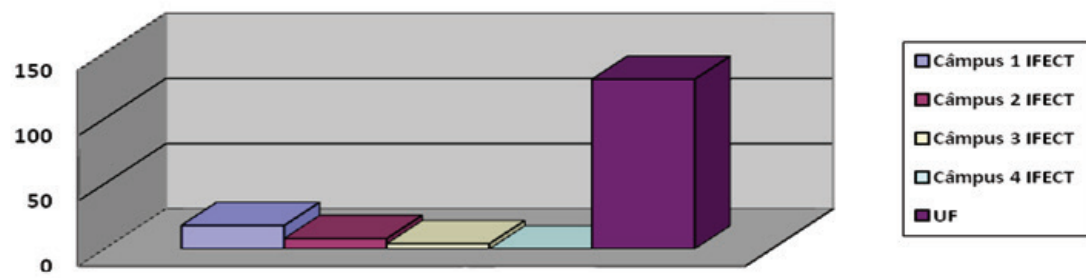

Gráfico 1: Comparação do número de alunos com deficiênciasno IFECT (Campus 1-4) e na UFF em 2013.

No final de 2013, o IFECT registrava o total de 2.956, enquanto o número de alunos com deficiência correspondia a 1,12\%. Comparando-se essa taxa percentual à taxa de $23,91 \%$ correspondente ao número de 45,6 milóes de brasileiros que declarou possuir algum tipo de deficiência no último Censo (IBGE, 2010) e o número de pessoas regitradas no mesmo Censo na Região Norte, constata-se significativa diferença. (Gráfico 2). Deve se considerar, ainda, o fato de que 5\% das vagas em todos os processos seletivos do IFECT são reservadas às pessoas com deficiência, o que corresponderia a 148 alunos (5\%),em 2013.

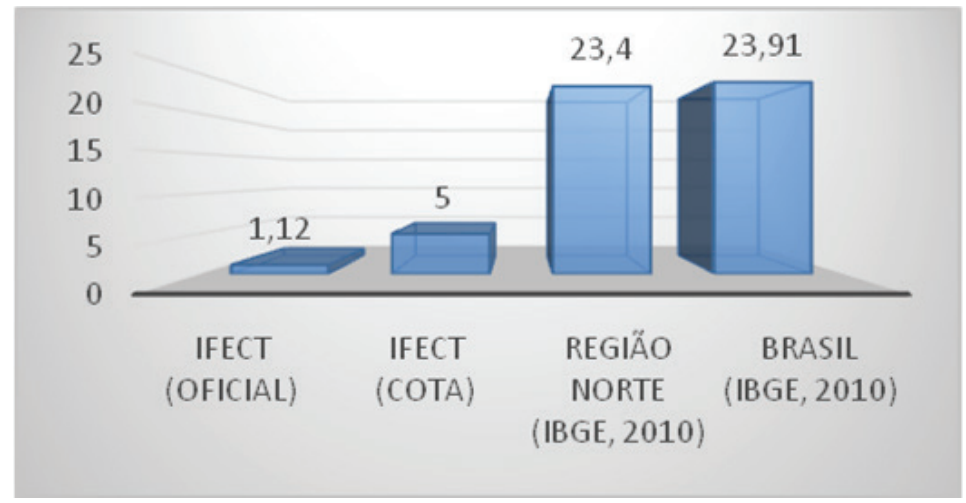

Gráfico 2: Percentual de Pessoas com Deficiência no IFECT, na Regiăo Norte e no Brasil.

Os campi 1 e 2 do IFECT são aqueles com maior número de estudantes com deficiências, provavelmente porque possuem o maior número de alunos matriculados. O campus 4 chama a atençáo, por ser o terceiro campi do IFECT em número de alunos e ainda não possuir nenhum aluno com deficiência. Enquanto isso, o campus 3 , que possui o menor número de alunos, tem dois alunos com necessidades especiais. (Tabela 1).

No campus 1, as deficiências registradas são a surdez, cegueira, baixa visão, síndromes e transtornos. No campus 2, as deficiências estão ligadas à surdez, dificuldades de locomoção, deficiência intelectual de nível leve e baixa visão. No campus 3, so há dificuldade de locomoção (Tabela 1). Na UFF, o censo realizado em 2011 mostrou a presença de alunos nas seguintes categorias: surdez, cegueira, dificuldades de locomoção, síndromes e transtornos, altas habilidade/superdotação e nanismo. 


\begin{tabular}{l|c|c|c|c}
\hline \multicolumn{1}{c|}{ Decifiências } & $\begin{array}{c}\text { Campus 1 } \\
\text { IFECT }\end{array}$ & $\begin{array}{c}\text { Campus 2 } \\
\text { IFECT }\end{array}$ & $\begin{array}{c}\text { Campus 3 } \\
\text { IFECT }\end{array}$ & $\begin{array}{c}\text { Campus 4 } \\
\text { IFECT }\end{array}$ \\
\hline Surdez & $\mathrm{X}$ & $\mathrm{X}$ & - & - \\
\hline Cegueira & $\mathrm{X}$ & - & - & - \\
\hline Baixa Visáo & $\mathrm{X}$ & $\mathrm{X}$ & - & - \\
\hline $\begin{array}{l}\text { Síndromes e } \\
\text { Transtornos }\end{array}$ & $\mathrm{X}$ & - & - & - \\
\hline $\begin{array}{l}\text { Dificuldades de } \\
\text { Locomoçáo }\end{array}$ & - & $\mathrm{X}$ & $\mathrm{X}$ & - \\
\hline Retardo Mental & - & $\mathrm{X}$ & - & - \\
\hline
\end{tabular}

Tabela 1: Comparação das Necessidades Específicas declaradas pelos Alunos matriculados nos Campido IFECT.

Assim como no IFECT, a UFF não possui registro de alunos que se identifiquem com altas habilidades/superdotaçáo no momento da matrícula, contudo a universidade possui um programa chamdo Altos Estudos para atender a esse tipo de público-alvo da educação especial na perspectiva da educação inclusiva, conforme previsto no Artigo 47, parágrafo $2^{\circ}$ da Lei de Diretrizes e Bases da Educaçáo. (BRASIL, 2013).

Os objetivos da Política Nacional da Educação Especial na Perspectiva da Educação Inclusiva, do Ministério da Educação, são ambiciosos e buscam a inclusão total dos alunos público-alvo da Educação Especial, destacando-se nesse estudo apenas aqueles que apresentam deficiência, considerando que a necessidade de mudanças mais significativas ocorre em relação a esse público-alvo da educação especial. Porém, quando analisamos o atendimento institucional oferecido em uma instituição de educação pública, verifica-se o quanto é longo o caminho a se percorrer até alcançar os objetivos almejados.

Uma das dificuldades observadas em relação ao atendimento institucional oferecido pelos Núcleos de Atendimento às Pessoas com Necessidades Específicas dos campi do IFECT, diz respeito à alta rotatividade de seus coordenadores. Do início de nossa pesquisa, de outubro de 2013 até o início de 2014, houve mudanças nas coordenaçôes em três dos quatro campi. Esta rotatividade, além de ser prejudicial ao andamento e desenvolvimento dos trabalhos, impede o aumentos da confiança dos alunos com deficiência na Instituição e nos coordenadores dos NAPNEs.

De acordo com Smith (2008), a educação especial deve prever um sistema de apoio e serviços correlatos, que envolva um grupo de serviços diversificados, com componentes individualmente determinados e aplicados. Ainda para Smith (2008, p. 55): "O termo grupo de serviço implica em disponibilizar diversos serviços em um mesmo local, facilitando o acesso e evitando deslocamentos desnecessários". No IFECT, o atendimento aos alunos com deficiência acaba ficando restrito ao NAPNE, mas a falta de recursos e materiais específicos para o atendimento a este público, segundo aos próprios coordenadores, limita e compromete a qualidade dos serviços prestados. 
Nas entrevistas realizadascom os coordenadores dos NAPNEs, verifica-se uma consciência da importância e relevância do papel desses órgãos para a efetiva inclusão dos alunos com deficiência. Todavia, talvez pelo fato desta consciência, detectamos nos discursos dos coordenadores certo sentimento de impotência e desânimo por não haver condiçóes materiais e de espaço físico para realizar um trabalho mais abrangente e eficaz em busca da inclusão efetiva destes alunos. A referida impotência e desânimo podem ser uma das razóes que causam a rotatividade de coordenadores referida anteriormente.

Em relação às ações acadêmicas, verificamos que os campi 1 e 2 do IFECT são os que realizam maior número de açóes, em parte pela demanda de atendimento ao maior número de alunos com deficiência (Tabela 2). $\mathrm{O}$ campus 4 , por não atender nenhum destes alunos, é o que menos açôes já realizou na área, como poderia ser de esperar, reafirmando o conceito de que a demanda impulsiona modificaçóes no sistema.

\begin{tabular}{l|c|c|c|c|c}
\hline \multicolumn{1}{c|}{ Açóes } & $\begin{array}{c}\text { Campus 1 } \\
\text { IFECT }\end{array}$ & $\begin{array}{c}\text { Campus 2 } \\
\text { IFECT }\end{array}$ & $\begin{array}{c}\text { Campus 3 } \\
\text { IFECT }\end{array}$ & $\begin{array}{c}\text { Campus 4 } \\
\text { IFECT }\end{array}$ & UFF \\
\hline $\begin{array}{l}\text { Interpretes de Língua } \\
\text { dos Sinais }\end{array}$ & $\mathrm{X}$ & $\mathrm{X}$ & - & - & $\mathrm{X}$ \\
\hline Ampliação de Materiais & $\mathrm{X}$ & - & - & - & $\mathrm{X}$ \\
\hline $\begin{array}{l}\text { Curso de Formação } \\
\text { para Professores }\end{array}$ & - & $\mathrm{X}$ & - & - & - \\
\hline $\begin{array}{l}\text { Orientaçáo aos } \\
\text { Professores }\end{array}$ & - & - & - & - & - \\
\hline Tutoria Acadêmica & $\mathrm{X}$ & $\mathrm{X}$ & - & - & $\mathrm{X}$ \\
\hline Rampa de Acesso & $\mathrm{X}$ & - & - & - & $\mathrm{X}$ \\
\hline Banheiros Adaptados & $\mathrm{X}$ & - & $\mathrm{X}$ & - & $\mathrm{X}$ \\
\hline
\end{tabular}

Tabela 2: Comparação das Açóes Acadêmicas e Estruturais adotadas pelo IFECT (Campus 1-4) e pela UFF em relação ao atendimento aos alunos com decifiência.

Ações práticas e que não requerem desembolso financeiro, como o desenvolvimento de avaliaçôes específicas para este público não são desenvolvidas, o que denota o quanto ainda há para avançar no atendimento aos alunos com deficiência, posto que ainda se trabalho por demandas e não por atendimento/acesso prévio da sociedade.

As ações estruturais, quando ocorrem, são as básicas e fundamentais para facilitar o acesso aos alunos com dificuldades de movimentação, como a construção de rampas ebanheiros adaptados. $\mathrm{O}$ campus 2 não possuía nem mesmo esses itens básicos no momento de realização desta pesquisa, dispondo de dois prédios alugados, um com escadas e o segundo com escadas e elevador.

Os principais problemas relatados, em relação ao atendimento aos alunos com deficiência, foram a falta de conhecimento dos professores em relação a este público e 
a falta de materiais e estrutura física para o atendimento especializado. A falta de conhecimento dos professores pode decorrer em virtude do grande número de professores que possuem apenas bacharelado, pois aqueles que passaram por licenciaturas, via de regras tiveram disciplinas sobre a temática inclusão e atendimento aos alunos com deficiência.

Em relação às ações específicas focadas nos docentes, as ações mais comuns foram a realização de oficinas e orientaçôes específicas. Um ponto que merece destaque é a atitude do campus 2 que realizou oficinas em parceria com o NAPI (Núcleo de Apoio Pedagógico a Inclusão) da Secretaria Estadual de Educação. Desta forma, aproveitam-se os conhecimentos e experiências dos profissionais deste órgão em benefício de professores e alunos do IFECT.

Quando questionados sobre a existência de espaços pedagógicos e/ou material didático específico para uso dos alunos com deficiência, apenas o campus 1 disponibilizava materiais específicos. Nenhum dos campi oferece espaços pedagógicos específicos aos alunos com deficiência. Este é outro ponto que denota o quanto ainda é necessário avançar na área.

No tópico sobre existência de formas de acompanhamento e verificação da inclusão especialmente voltada aos alunos com deficiência, apenas os campi 1 e 2 realizam tal acompanhamento por meio de visitas individualizadas. Os campi 3 e 4, náo realizam devido ao baixo número de alunos com deficiência ou sua ausência entre o corpo discente.

Terra e Gomes (2013) relatam que a inclusão escolar implica, efetivamente, em um aprimoramento constante dos professores, com a apresentação de instrumentos e referenciais que evoluam e desenvolvam as práticas pedagógicas aplicadas por eles. Tal evolução e desenvolvimento necessitam de açóes acadêmicas e pedagógicas específicas, concebidas para atender as especificidades dos alunos com deficiência. Como já verificado anteriormente, no IFECT as açóes acadêmicas e pedagógicas são limitadas e insuficientes para garantir um atendimento pleno e eficaz aos alunos com deficiência.

Segundo Mendes (2006, p. 397), a educação especial no Brasil não sofre apenas com a falta de acesso ao ensino. Junto estáo a falta de educação apropriada pela falta de profissionais qualificados e a falta generalizada de recursos (Tabela 3). Este é o panorama que se percebeu no IFECT, quando da análise do discurso dos coordenadores dos NAPNES. As categorias encontradas foram falta de conhecimento dos servidores, falta de materiais e equipamentos pedagógicos e falta de estrutura física,comprometendo a qualidade dos serviços prestados aos alunos com deficiência. Ao contrário, na UFF, a categoria mais acentuada foi a viabilidade financeira para a execução de obras e projetos. 


\begin{tabular}{l|c|c|c|c|c}
\hline \multicolumn{1}{c|}{ Problemas } & $\begin{array}{c}\text { Campus 1 } \\
\text { IFECT }\end{array}$ & $\begin{array}{c}\text { Campus 2 } \\
\text { IFECT }\end{array}$ & $\begin{array}{c}\text { Campus 3 } \\
\text { IFECT }\end{array}$ & $\begin{array}{c}\text { Campus 4 } \\
\text { IFECT }\end{array}$ & UFF \\
\hline $\begin{array}{l}\text { Falta de conhecimento } \\
\text { dos servidores }\end{array}$ & $\mathrm{X}$ & $\mathrm{X}$ & $\mathrm{X}$ & - & - \\
\hline $\begin{array}{l}\text { Falta de Materiais } \\
\text { e Equipamentos } \\
\text { pedagógicos }\end{array}$ & $\mathrm{X}$ & $\mathrm{X}$ & $\mathrm{X}$ & - & - \\
\hline Falta de Estrutura Física & - & $\mathrm{X}$ & $\mathrm{X}$ & - & - \\
\hline $\begin{array}{l}\text { Viabilidade Financeira } \\
\text { para execução de obras/ } \\
\text { projetos }\end{array}$ & - & - & - & - & $\mathrm{X}$ \\
\hline
\end{tabular}

Tabela 3: Categorias identificadas no IFECT (campus 1-4) e na UFF em relação ao atendimento aos alunos com deficiência.

Outro ponto identificado foi a falta de uma coordenação geral das açôes e atividades reaizadas pelos NAPNEs, do IFECT. As entrevistas indicaram que o planejamento e as açóes ocorrem de maneira individual, em cada campi, sem uma proposta de política institucional para todos os alunos matriculados. Não há troca de informaçôes, o que compromete o intercâmbio de boas práticas entre os campi.

Comparando-se as açóes de acessibilidade realizadas em diversas áreas no IFECT e na UFF, constata-se a necessidade de aprimoramento das ações do IFECT para garantir tanto a acessibilidade quanto à inclusão dos alunos com deficiência. Constatou-se que na UFF, já foram criados diversos meios para garantir diferentes tipos de acessibilidade.

Com a expansão física aprovada pelo REUNI, a UFF investiu em obras e reformas de 40 unidades localizadas em Niterói e mais três fora da Sede, como as dos municípios de Pádua, Rio das Ostras e Campos dos Goytacazes. A UFF ${ }^{1}$ possui o Núcleo de Acessibilidade e Inclusão - Sensibiliza UFF², vinculado a Pró-Reitoria de Assuntos Estudantis, $\mathrm{PROAES}^{3}$, que visa o fomento da implantação e consolidação das políticas inclusivas na UFF e diminuição de barreiras. O Sensibiliza já realizou o primeiro censo de estudantes de graduação e pós-graduação, professores e funcionários técnico-administrativos com deficiência; busca a identificação dos alunos desde a matrícula após o vestibular; apoia a PROAES na execução do Programa Bolsa de Apoio ao Estudante com Deficiência; acompanhaos alunos com deficiência em seus diferentes cursos pelo contato direto com as coordenaçóes de cursos, professores e com o próprio aluno; oferece cursos de capacitação e sensibilização para a comunidade acadêmcia; divulga eventos; em 2014, o Sensibiliza criou a Ouvidoria, mais uma canal de comunicação direta com os alunos, professores e técnicos-administrativos com deficiência, com vistas a eliminação de barreira atitudinais e comunicacionais. Vinculados ao Sensilbiliza estáo os intépretes de Língua de Sinais, concursados para o quadro efetivo de técnico-administrativos da univerisdade. Para garantir a acessibilidade instrumental e metodológica, o Sensibiliza, com apoio da PROAES, disponibilizacomputadores, laptops, cadeiras de rodas, entre outros recursos, para pessoas com 
deficiência. Instalou a linha Braille em dois campi (Niterói e Campos dos Goytacazes) para alunos cegos, composta de Linha Braille, impressora Braille, tupa eletrônica e escâner. Além disso, o Sensibiliza UFF mantém parceria com departamentos diversos a fim de apoiar açóes e projetos desenvolvidos em prol dos alunos matriculados em cada curso.

A diversidade humana implica a consideração das diferenças, sejam estas decorrentes de deficiência, doenças, cor da pele ou nível socioeconômico. Na perspectiva da convivência com as diversidades entre sujeitos, propôem-se a organizaçấo de uma sociedade inclusiva (LIMA, 2010). Para alcançar tal inclusão, a acessibilidade necessariamente precisa fazer parte da pauta, preocupações e objetivos das Instituiçóes de Ensino.

Outro dado que revela o quanto o IFECT ainda precisa aprimorar o atendimento aos alunos com deficiência é o fato de que, na época da elaboração desse estudo, náo havia vagas reservadas para pessoas com deficiências em nenhum estacionamento dos campi.

\section{Considerações finais}

Para Lima (2010) o desenvolvimento da Educação Especial é um processo dinâmico, dialético e contínuo e destaca a importância das interaçóes e nas trocas enriquecedoras. No IFECT, percebe-se a ausência de uma coordenação central das açóes dos NAPNES, o que dificulta a caracterização de uma política pública institucional voltada para pessoas com deficiências. As açóes individualizadas impedem a troca de experiências o que poderiam fortalecer a continuidade das açôes e o aumento da probabilidade de sucesso dos objetivos.

Sendo as açôes individualizadas e não havendo interaçóes e trocas que certamente contribuiriam para troca de experiências que alcançaram sucesso. Com isso, o IFECT é mais uma instituiçáo de ensino que contribui para que os alunos com deficiência, mesmo em pequena quantidade, não tenham garantidas as condiçóes essenciais de acesso, permanência e sucesso escolar (MENDES, 2010, p. 399).

Os dados levantados mostram a necessidade de aperfeiçoamento das condiçóes institucionais para o atendimento aos alunos com deficiência no IFECT, uma vez que o Instituto reserva 5\% das vagas em seus processos seletivos a pessoas com deficiência, o que não tem sido utilizado pelos mesmos.

Verificou-se que a UFF adota açóes e processos na área arquitetônica, acadêmica, estrutural, de materiais e equipamentos específicos para alunos com deficiência, além de ações específicas com os docentes e técnico-administrativos que poderiam auxiliar no planejamento de programas destinados aos alunos com deficiênciade outras instituições de ensino, como uma instituição nova, que ainda se encontra em fase de implantação, um Instituto Federal (IFECT). Como tudo o que é novo, precisa sempre ser aperfeiçoado, ainda há muito o que melhorar mesmo na UFF que já possui um conjunto de açóes, processos e experiências em processo. Contudo, sua experiência pode servir de parâmetro útil e relevante para indicar caminhos para, 
com as devidas adaptaçóes, aperfeiçoar o atendimento aos alunos com deficiência não só no IFECT, mas em outras unidades da Rede Federal de Educação Profissional, Científica e Tecnológica.

O que fica claro é que as as açóes, processos e experiências executadas pela UFF promovem a acessibilidade dos alunos com deficiência. A mesma acessibilidade que deve ser continuamente buscada por todas as Instituiçóes de Ensino que evetivamente buscam a inclusão dos alunos com deficiência.

Como sugestão para o acompanhamento das açôes de implementação de políticas de inclusão que ainda vão ser iniciadas no IFECT, recomenda-se o uso de ferramentas administrativas, como o benchmarking, a fim de comparar os resultados apresentados entre as duas instituiçóes de ensino superior aqui estudas na questão da acessibilidade. Tal comparação favorecerá a análise dos níveis alcançados e a sua superação.

O presente trabalho pesquisou os respectivos coordenadores dos Núcleos de Atendimento as Pessoas com Necessidades Específicas (NAPNE) e avaliou o ambiente institucional quanto a acessibilidade aos alunos com deficiência. Novas pesquisas envolvendo os professores e os alunos com deficiência para verificação mais detalhada das mudanças necessárias para aprimorar o atendimento aos alunos com deficiência podem ser importantes para nortear futuras açóes administrativas e acadêmicas do respectivo Instituto Federal.

\section{Referências}

BARDIN, L. Análise de Conteúdo. 3.ed. Lisboa: Ediçôes 70. 2002.

BRASIL. Política nacional de Educaçáo Especial na perspectiva da Educaçáo Inclusiva. Brasília: MEC/ SEESP, 2008. Disponível em: <http://portal.mec.gov.br/seesp/arquivos/pdf/politica.pdf>. Acesso em: 07 abr. 2014.

BRASIL. Ministério da Educação. Lei de Diretrizes e Bases da Educaçáo Nacional. LDB 9.394, de 20 de dezembro de 1996.Disponível em: <http://www.planalto.gov.br/ccivil_03/Leis/L9394.htm>. Acesso em: 03 nov. 2014.

CAIADO, K.; JESUS, D. M.; BAPTISTA, C. R. (Orgs.). Professores e educaçáo especial: formação em foco. Porto Alegre: Edição/CDV/FACITEC, 2011.

CARDOSO, F. S.; et al. Proteins: proposing the construction of a Didactical Multimedia Material to get Teachers and Interdisciplinarity Together. Advances in education, v. 03, p. 1-7, 2014.

CHAVES, S. Inclusão para todos. In: Escola Pública, v. 37, p. 20-25, 2014.

CAREGNATO, R. C. A; MUTTI, R. Pesquisa qualitativa: análise de discurso versus análise de conteúdo. Texto \& Contexto - Enfermagem, v. 15, n. 4, p. 679-84, 2006.

COHEN, L; MANION, L; MORRISON, K. Research Methods in Education. 5. ed. Inglaterra: Editora RoutledgeFalmer; 2001.

DELOU, C. M. C.; et al. A Educação Inclusiva e a Escola de Inclusão. In: Formando para Continuamente Formar. Fio da Ação, v. 2, p. 51-71, 2012.

DELOU, C.M.C.; et al. School of Inclusion: The contribution of a Federal University to the Inclusive Education. Advances in Education, v. 1, p. 04-10, 2012.

DELOU, C.M.C.; et al. A universidade, a escola e as necessidades especiais: Como melhorar? Como contribuir?. In: Revista Praxis On-Line, v. 6, p. 11-17, 2012. 
DELOU, C. M. C.; et al. A surdez e a formação continuada: o caso do mestrado profissional em diversidade e inclusão da UFF. In: XII Congresso Internacional e XVIII Seminário Nacional do INES, 2013, Rio de janeiro. Educação de Surdos em Países Há línguas em português (José Saramago). Rio de Janeiro: INES, Departamento de Desenvolvimento Humano, Científico e, 2013. v. 12. p. 599-603.

GUERREIRO, E. M. B. R. A acessibilidade e a educaçáo: um direito constitucional como base para um direito social da pessoa com decifiência. In: Revista Educaçáo Especial, Universidade Federal de Santa Maria, v. 25, n. 43, p. 217-232, maio/ago. 2012.

LIMA, P. A. Educação inclusiva: indagaçôes e açôes nas áreas da educação e da saúde. São Paulo: Avercamp, 2010.

LYRIO, E.; et al. A monera kingdom atlas for presenting cell morphology and biotechnology for visually impaired students. Creative Education, v. 05, p. 290-296, 2014.

MAZZOTTA, M. J. S. Educaçáo especial no Brasil: histórias e políticas públicas.6á. ed. São Paulo: Cortez, 2011.

MENDES, E. G. A radicalização do debate sobre inclusão escolar no Brasil. Revista Brasileira de Educaçáo, v. 11, n. 33, set./dez. 2006, p. 387-559.

MERÇON, T.; et al. Libras e sexualidade: comparação de sinais com a American SingLanguage para a produção de materiais didáticos sobre temas de importância à saúde da mulher. In: XII Congresso Internacional e XVIII Seminário Nacional do INES, 2013, Rio de Janeiro. Educação de Surdos em Países de Língua Portuguesa Há línguas em português (José Saramago). Rio de Janeiro: INES, Departamento de Desenvolvimento Humano, Científico e, 2013. v. 12. p. 604-610.

REDE FEDERAL DE EDUCAÇÃO PROFISSIONAL, CIENTÍFICA E TECNOLOGICA. Histórico da Rede Federal de Educaçáo Profissional, Científica e Tecnológica. Brasília: MEC, 2013. Disponível em: <http:// www.redefederal.mec.gov.br>. Acesso em: 01 ago. 2013.

SMITH, D. D. Introduçáo à educaçáo especial: ensinar em tempos de inclusão. 5 ed. Porto Alegre: Artmed, 2008.

SOUZA, R. de.; et al. Blindness and fungi kingdom: a new approach for teaching a biological theme for students with special visual needs. Creative Education, v. 3, p. 674-678, 2012.

TERRA, R.N.; GOMES C.G. Inclusão escolar: carências e desafios da formação e atuação profissional. Revista Educação Especial, Universidade Federal de Santa Maria, v. 26, n. 45, p. 109-124, jan./abr. 2013.

TRIVIÑOS, A. Introduçáo à pesquisa em ciências sociais: A pesquisa qualitativa em educação. 4.ed. São Paulo: Atlas; 2008.

\section{Notas}

${ }^{1}$ http://www.uff.br/reuni/index.php?option=com_content $\&$ view=article\&id=175\&Itemid=168.

${ }^{2}$ http://www.prograd.uff.br/sensibiliza/.

${ }^{3}$ http://www.proaes.uff.br/.

\section{Correspondência}

César Gomes de Freitas - Instituto Federal do Acre, Campus Rio Branco. Avenida Brasil n. 920, Conjunto Xavier Maia, CEP: 69903-068 - Rio Branco, Acre - Brasil.

E-mail: cesar.freitas@ifac.edu.br - cristinadelou@globo.com - hcastrorangel@yahoo.com.br

Recebido em 05 de novembro de 2014

Aprovado em 22 de junho de 2015 